\title{
EL LATÍN DE LOS CONQUISTADORES EN "TENOCHTITLAN" DE JOSÉ LEÓN SÁNCHEZ
}

\section{THE LATIN OF THE CONQUERORS IN "TENOCHTITLAN" BY JOSÉ LEÓN SÁNCHEZ}

\section{Henry Campos Vargas*}

\author{
RESUMEN
}

Este artículo muestra los diferentes niveles del latín empleados por José León Sánchez en su novela Tenochtitlan. Esta lengua es una de las vías para representar el poder de Roma, España y la Iglesia Católica en el proceso de dominación de México.

PALABRAS CLAVE: LATÍN * ROMA * TENOCHTITLAN * MÉXICO * ESPAÑA

ABSTRACT

This paper shows different levels of latin used by José León Sanchez in his novel Tenochtitlan. This language is one of the ways in order to control México.

KEYWORDS: LATIN * ROME * TENOCHTITLAN * MEXICO * SPAIN 


\section{INTRODUCCIÓN}

La conquista fue un proceso de dominación militar, religiosa, lingüística... Seducido por esta última problemática, León Sánchez describe en esta obra pictogramas aztecas, mensajes por medio de señales multicolores de humo, tambores con mensajes cifrados, historias reflejadas en el entramado de nudos, amén de los contrastes entre los dialectos nativos y las lenguas de los conquistadores. Estas últimas destacan en algunos pasajes, como el siguiente:

El Fuerte de Xólotl era una isleta en mitad del lago. Una isleta muy hermosa, rodeada de jardines y chinampas.

El ejército de Cortés estaba en formación, pero unos a otros se hacían bromas. Se escuchaban palabras en griego, italiano, portugués... (1986: 137).

En medio de este universo lingüístico de principios del siglo XVI de nuestra era, aparece una lengua, el latín, que representa un espacio de extrañamiento lingüístico, puesto que se trata de una lengua sin habla. No es casual, pues, que la lengua latina no aparezca enlistada en la serie de las hablas de las políglotas tropas, entre las que se contaban hombres griegos, judíos, napolitanos, venecianos, moros, conversos nuevos o catalanes (1986: 74), e incluso, portugueses como Juan Pinto (1986: 402).

\section{EL LATÍN: UNA DE ENTRE LAS LENGUAS DE LA NOVELA}

Cuitláhuac, uno de los personajes, manifiesta en un informe ante Moctezuma que el pueblo de Tenochtitlan aprende de un prisionero, el soldado Lerma, sobre la existencia de una extraña lengua entre los conquistadores:

-Y en esa forma que les cuento, pronto sabremos el secreto de todas sus palabras... Hemos sabido que tienen una forma de hablar que nadie entiende, solamente unos pocos de ellos, en especial los sacerdotes. En sus cantos religiosos van diciendo esas palabras que nadie entiende, ni siquiera el gran enviado (1986: 112).
El latín aparece preponderantemente asociado a la religión, en particular, al catolicismo, con menoscabo de registros como el latín cultivado por el humanismo europeo en sus vertientes filosófica, relaciones internacionales...

Parece que los tenochas (neologismo acuñado por José León Sánchez para referirse a los habitantes de este pueblo) aprendieron algo de latín:

-Doña Marina me ha dicho que entre algunos de estos indios se os ha puesto un nuevo nombre.

—¿Qué nombre?

- Señor de la furia...

— ¿Señor de la furia? Me gusta... Es casi igual al que los indios de Santo Domingo le pusieron al señor almirante Cristóbal Colón, domine furori (sic) por eso me gusta (1986: 122).

domine en realidad sería el vocativo de dominus, voz esta última que debió ser la consignada en el texto. En igual sentido, la frase nominal completa habría sido dominus furoris (señor de la ira), con el adjetivo en caso genitivo, no dativo, como consigna el texto por error.

Para el ejército de Cortés, la lengua de Roma es oscura, se trata de un xenismo que, retóricamente, marca negativamente la expresión: puede crear un distanciamiento tal con el oyente que llegue a producir la ininteligibilidad del mensaje. Este fenómeno puede ser experimentado por el propio lector de la novela en caso de no estar familiarizado con esta lengua.

La extrañeza del latín para con los conquistadores corre paralela a la del náhuatl, la lengua de los tenochas, con respecto a los pueblos amerindios conquistados por los aztecas, pues será una lengua igualmente ajena.

Esta propiedad, el ser ajena una lengua que irremisiblemente hay que usar, es producto del poder, de la dominación. La presencia de la lengua de los poderosos es un recordatorio del status de dominación: los indígenas conquistados debieron aprender y usar una lengua que no era la propia, primero, el náhuatl, luego, el 
castellano. Los conquistadores también veían marcado su quehacer cotidiano por la presencia de un poder lejano y presente, con la desventaja de que no era tan accesible para todos.

La imposición del náhuatl databa:

(...) desde que el señor viejo, enamorado del idioma, ordenó que sólo se hablara náhuatl en todos los territorios, lo que se hizo por orden de Techotlatzin (1986: 340).

Malintzin, a quienes los habitantes de Tenochtitlan llamaban "el loro" nahuachichimeca de Cortés, ha sufrido en carne propia este extrañamiento lingüístico, pues:

Las primeras palabras que aprendía, que no eran las de mi madre, que no eran las de mi padre, fueron náhuatl (1986: 81).

A su manera de ver:

Los habitantes de Tenochtitlan son broncos en el hablar, hablando de ellos mi madre decía: "Son los que hablan bronco..." (1986: 83).

Quizás este rasgo explique por qué al ingresar el ejército de Cortés en Tenochtitlan, se sirvieron de un guerrero de Tlaxcala en los siguientes términos:

Adelante, sólo a veinte pasos adelante, venía el vocero de Tlaxcala que gritaba en nuestro idioma avisando que toda mujer, todo niño, todo hombre, todo anciano, toda flor, toda hoja, toda rama de árbol que osara obstruir el ingreso del ejército de Castilla sería cortado en dos por la mitad $y$ destinado a ser alimento de los perros. Eso decía el guerrero de Tlaxcala, así lo repetía con voz de trueno (1986: 129).

El contraste de la lengua de los tenochas es patente al confrontarla con otros dialectos, por ejemplo:

La gente de Chaco (por ejemplo) no habla como la de Tenochtitlan, sino que usa un lenguaje suave, como el algodón, o el pétalo de las flores (1986: 126).

El autor incluso aprovecha el prestigio del náhuatl para mostrar procesos de discriminación lingüística durante la fiesta de Toxcatl, celebrada al pie del Templo Mayor. Entre la multitud de pueblos que se acercaban a la capital estaban:

los de Mecatepec y los que se reían de ellos y les llamaban gente totonaca, la tonta, porque arribaban de lejos y no hablaban el idioma culto de los nahuatlas (1986: 187-188).

En el conjunto de lenguas autóctonas, incluso hay espacio para lenguas extrañas, como cuando inicia la expedición a Yucatán, donde encuentran a:

(...) una mujer que no era de ahí, ni de tierra adentro, ni de tierra afuera. Hablaba la lengua de la gente de cerca de santo Domingo y de Cuba (1986: 336).

Los españoles, empero, aprenderán náhuatl, no como un pueblo dominado, sino para controlar el discurso en sus relaciones con los habitantes de Tenochtitlan, pues, de esta manera, lograrían independizarse de traductores como Malintzin, quien era consciente de que al aprender los españoles el náhuatl, se tornaría en un objeto prescindible (p. 367).

También el náhuatl decaerá paulatinamente al imponerse el español, proceso que comenzó con la derrota de Tenochtitlan, cuando las mujeres $y$ hombres son exterminados. Igual suerte toca a los libros, libros que describían los "idiomas de la tierra" (1986: 279) entre otros muchos saberes. La quema de la biblioteca de Nexahualcóyotl representaba para una sacerdotisa un:

(...) día aciago, seresmos (sic) mudos eternamente, sin saber de la huella que dejaron nuestros antepasados por la vida (1986: 279).

Respecto a los niños, Cortés ordena:

- Haced de ellos lo que hacía el gran Alejandro con las piezas de Persia, ¡castradles! (1986: 406).

\section{ROMA Y EL LATÍN: SÍMBOLOS DE LA CULTURA EUROPEA}

En la novela predomina el registro religioso del latín, aspecto en el cual la obra se 
inserta en una atávica tradición de la literatura costarricense. Su funcionalidad en la obra está relacionada permanentemente con Roma, en cuanto símbolo de dominación, cultura y globalización.

Roma y el latín son un referente continuo en ese ambiente. Esto explica su presencia indirecta en la carta que Cortés dirige a los reyes de España, donde describe las Ochenta Reglas de la Sabiduría que componen el Código de Nezahualcóyotl:

Para merecer el título de muy altísimo Juez destos tribunales, tienen que estudiar mucho y en forma tal que las leyes son más sabias que las Siete Partidas y mucho más profundas que las leyes de Justiniano. Tienen leyes que cuidan que los niños asistan a la escuela a los siete años de edad; contra la ebriedad, la vagancia, la maldad de corazón, la destrucción de los árboles cerca de las fuentes donde recogen el agua. Leyes que protegen a las viudas y a los huérfanos; toda persona debe conocer todas y cada una de las ochentas leyes (...) (1986: 151).

Más adelante, prosigue la carta:

Hablando con muchas de estas piezas, hemos sabido que Moctezuma y sus reinos viven sumidos en harto temor, envidia $y$ odio. Hemos visto un sistema de baños calientes, con albercas junto a ellos que son iguales a los que Plinio contaba que existían en la augusta ciudad de la Roma Imperial. Mas aquí los palacios son más grades $y$ hermosos que los que tenía Roma en la época de Marco Aurelio $y$ los de hoy, según hanme dicho los soldados que la conocen y que terminan diciendo que toda la belleza de Venecia no puede igualarse con aquesta ciudad de México Temiztlan (1986: 153).

Esta presencia de la Urbs, la confirman las palabras de Andrés de Tapia a Xiconténcatl el joven, en Tlaxcala:

(...) pero sucede que frente a las costas de nuestra gran nación existe un mar ancho y largo que llamamos desde el tiempo de Roma Mare Nostrum y en sus orillas habitan los infieles (1986: 291).

Es claro que, en el pensamiento de la obra, España se ha identificado con Roma, representada en sus más grandes símbolos: el mar, la ciudad, el derecho, sus gobernantes y su lengua. Para el derecho, se apela a Justiniano, el gran compilador de su sistema jurídico; en cuanto a sus gobernantes, a Marco Aurelio, El Sabio, el último de los llamados Cinco Buenos Emperadores, quien gobernó del 161 al 180. Roma y sus gladiadores también son el parámetro de comparación en un combate ofrecido para entretener a Cortés y a su gente durante su primera visita a la capital azteca (Roma de los Césares es precisamente la frase usada, p. 168). De este modelo, se aprovecha incluso para describir a María Estrada, esposa del sargento Estrada, al poner en sus labios las siguientes palabras, con ocasión de la discusión que le permitió acompañarlo en la aventura militar:

- Camino como una burra de Almeria; soy terca como el río Guadalquivir que jamás se ha devuelto; tengo todos los conocimientos que atesora Santi Ponte desde la época de los romanos en Sevilla; sé cocinar, lavar, haceros el amor. ¿Por qué dudáis de mí? (1986: 158).

Grecia aparece indirectamente a través de la figura de Alejandro Magno. De los hechos militares de Hernán Cortés, un anónimo soldado catalán escribe:

Juventud sí tenía Cortés. Coraje, como pocos de los soldados en la historia de Castilla, la vieja, la nueva. Un día estará en el más grande de todos los libros castellanos, junto a César, Alejandro, Aníbal, y, a fe mía, que se lo merecen (1986: 328).

Esta percepción es continuamente compartida por la soldadesca, así al tratar de escapar de Tenochtitlan se lee:

Los soldados estaban contentos, y esa noche admiraban y prometían vivir al lado del señor capitán que había tenido tales ideas, no comparadas con las acciones del César, ni del hijo de Filipo de Macedonia (1986: 225). 
La ambición y planes de Cortés son descritos con base en estos dos referentes:

Martín López pensaba en las palabras de Hernán Cortés y tenía que reconocer una verdad, atrás quedaban las ideas de César para destruir las Galias y llevar esclavos a Roma; atrás quedaban las guerras de Aníbal en los duros caminos de Iberia... atrás quedaban las historias de Alejandro, el hijo de Filipo de Macedonia. La idea era audaz, única, incontenible, como el corazón de Hernán Cortés. Pensó que todo eso era necesario, porque los guerreros de México iban más allá de los moros a los que se enfrentó el Gran Capitán. El alumno de Aristóteles había caminado adelante guiado por los vaticinios del Olimpo, por los augurios de Delfos, por los sueños de su amante, otro hombre. Pensaba en César, general de los romanos, que de joven había tenido que servir de mujer a un señor de las Galias para aprender sus triquiñuelas en la guerra. $Y$ el sueño de Hernán Cortés quería superarlos a todos (1986: 306).

El impresionante ambiente cultural de Tenochtitlan, como el de Texcoco, son descritos sobre la base de la ecuación Roma-Grecia:

Ahora estaba seguro (Martín López) de que esos indios habían inventado la escritura y el arte de hacer libros antes de que se conociera en las Universidades de Castilla... Martín López estaba seguro que tenían un arte de números superior a los griegos y a los romanos; ya sabía que esos hombres conocían la medicina en forma mejor que los árabes (...) Terminó Martín por entender que Tenochtitlan era una ciudad romana, pero que Texcoco era una ciudad griega, como la Atenas de Platón, de Pericles, de Sócrates... Cuando escuchó a Ixtlixóchitl recitar los pensamientos de su augusto abuelo, el señor Nezahualcóyotl, comentó con el tesorero Alderete:

-Después de escuchar al nieto, ya entiendo que su abuelo podía sentarse a dialogar con Sócrates en cualquier plaza de la vieja Atenas... (1986: 306-307).

Roma y Grecia son también los ejes para comparar las acciones de los aztecas en materia militar, en particular, su empleo del silencio (véase 1986: 209), una estrategia sin precedentes en el hijo de Filipo, en César o Aníbal, según el criterio de León Sánchez.

\section{LA HEGEMONÍA DEL LATÍN RELIGIOSO}

El capítulo $\mathrm{V}$ marca el incipit, el comienzo de la invasión. La descripción memora los pasajes del Génesis:

Chalchiucuyehcan es el nombre del lugar desde donde todo se empezó a escribir sobre la arena (1986: 49).

De inmediato, tiene lugar la primera mención del latín, un latín de dominación que aprovecha un intertexto político y religioso del siglo III de nuestra era:

Sobre los palos mayores se agitaban las banderas de Carlos v y Hernán Cortés, con sus palabras en latín, que eran todo un reto al destino de nuestra raza, de nuestros dioses:

Amici seguamor (sic) crucem, et si nos filem (sic) habemus, vere in hoc signo vicemus (sic). $y$ decían:

Las palabras se reflejaban sobre el mar

\section{Hermanos y compañeros: \\ sigamos la señal de la cruz con fe verdadera porque con ella venceremos (1986: 49).}

El agua es el elemento sobre el que el espíritu divino se pasea antes de la creación. Es un principio de la creación, espejo que trasforma, da un giro al mundo real, que será el resultado de la narración de la novela. Por ello convergen "arena" y "agua", símbolos opuestos que aluden a la materia primigenia, al cambio, al devenir.

Escasas cuatro páginas adelante, Hernán Cortés aparece en una escena mítica:

En seguida, tomando una cruz que tenía un soldado en sus manos, la clavó en la 
arena y continuó: - En nombre de nuestro Señor, nombro a esta tierra de bestias la buena tierra de Vera Cruz, de la única cruz, de la cruz de la verdad. Repetid conmigo (1986: 53).

Este topónimo es repetido de inmediato por las tropas y asume real importancia en la celebración del primer Cabildo en México, el de la Villa Rica de la Vera Cruz (pp. 75-77). Aparecerá continuamente hasta el final de la obra, a la altura de la página 305.

La inserción de la escena de una misa en la narración, antecedida por un discurso de obediencia y sumisión pronunciado por el padre Juan Díaz a Cortés, donde hace hincapié en el pago del diezmo, es también un contexto propicio para nuevas apariciones del latín:

El padre Juan Díaz continuó la misa en latín. Al final, lleno de emoción, después de besar la copa y ponerse de rodillas, volteó a mirar a los soldados y levantando sus manos y sus brazos blancos en forma de cruz, dijo:

\section{—Dominus vobiscum.}

- Et cum Spiritu tuo - respondió Fray Bartolomé de Olmedo, con una voz muy hermosa.

\section{— Benedicto Dei, omnipotentis...}

Y volviendo todo el cuerpo hasta el público hizo la señal de la cruz y repitió:

-Patre (sic), et Filii, et Spiritus Sancti.

-Amén-dijo Fray Bartolomé.

-Amén- repitió Cortés lleno de mansedumbre y con él todo el ejército en alta voz, como un eco.

-Ite misae (sic) est.

—Deo gratias (1986: 70).

El latín de las citas precedentes muestra serios yerros en la morfología de las palabras y la gramática: seguamor en vez de sequamor, filem por fidem, patre en lugar de patris, el plural misae, cuando lo procedente era el singular misa.
Respecto al estandarte de Cortés, en efecto, tenía una leyenda en latín, a saber: amici sequamor crucem; si enim fidem habuissimus in hoc signo vincemus (de Alós, 1961: 132), es fácil corroborar los errores en la transcripción.

Una misa es también el espacio para el latín en la batalla del Valle de Otumba, aunque las circunstancias son distintas: Cortés, sus hombres y aliados están rodeados por el ejército azteca, todo vaticina un holocausto:

Pero no había duda, ésa sería la última batalla que algún día contaría la historia, en los campos de magueyes de México, sobre los capitanes de Castilla. Unos y otros se despedían, rezaban. Los sacerdotes celebraban una precipitada misa de campaña.

_Et (sic) misa est... (1986: 248).

Esta última expresión, pronunciada al concluir la celebración litúrgica, es propia del latín eclesiástico, su sentido es: "la oración se ha enviado al Señor". Aparece por última vez en la página 333, al describir la misa solemne que antecede a la batalla de la laguna de Texcoco. De esta misa, Cortés pidió expresamente que fuera "hermosa" y "que nos escuche Dios". Aquí León Sánchez la transmite como est misa est, destacando el interés de los jefes de Tlaxcala, Huexotzinco, Cholula y también Ixtlixóchitl, por la nueva religión de los cristianos; todos ellos, ahora con los apelativos de don Felipe, don Carlos, don Santiago, don Pedro, don Miguel, don José, don Juan, doña Rita Rosa, don Cosme, doña Adelia.

El latín es también una lengua académica: tal y como reconoce Hernán Cortés durante una narración etiológica de Malintzin sobre la construcción de Tenochtitlan, aunque no ejemplifica su uso:

El gran Nezahualcóyotl decía de ellos que eran tan sabios que podían dialogar hasta con su propio corazón.

- ¡Dialogar con su propio corazón! ¿Qué dirían mis antiguos maestros de Salamanca, donde pasé estudiando latín ocho semanas, al escuchar estas palabras? (1986: 149). 
No obstante, la verdad y los frutos de tal estadía los había confesado Cortés al Capitán Juan Velázquez de León, al tramar la constitución del Cabildo de la Villa Rica de la Vera Cruz:

-Ya se teje vuestra leyenda...

—Equivocada... Mi estadía en Salamanca no pasó de tres meses, cuando tenía quince años de edad y nunca precisé cumplir siquiera con las clases de latín que recibía... Ya veis que está mal esa leyenda (1986: 73).

El cultismo natura aparece en la página 79 , en la frase "requerimiento de natura", donde se pretende apelar a un evento natural como causa de la pérdida de los galeones españoles, ocultando así el carácter político de su destrucción.

La lengua de Roma, su espacio y simbolismo son un continuo referente en la obra, sin embargo, el latín de carácter religioso predomina entre las manifestaciones políticas, jurídicas y culturales. En esta lengua están escritas las oraciones de absolución pronunciadas sobre una masa de prisioneros a punto de ser quemados vivos:

-Ego te absolvo a pecatis tuis. In nomine Patre (sic) et Filii, et Spiritus Sancti, Amén... (1986: 178).

Nuevamente, se emplea el ablativo en vez del genitivo en la fraseología sígnica del catolicismo. En esta dolorosa escena, Cuauhpopoca, el Señor de las Costas, de las Fronteras, es chantajeado para que entregue los mapas de la defensa del imperio a cambio de la vida de su hijo de doce años. Su respuesta es un salivazo hacia Hernán Cortés, el corolario es obvio: todos los prisioneros son incinerados. La escena acaba en medio de las oraciones en latín de Fray Bartolomé de Olmedo y el sacerdote Juan Díaz. Un brillante contrapunto.

Un efecto semejante se consigue en la subasta de esclavos, donde un "padrote" de piel negra (el negro Mandinga) es exhibido en toda su facultad generativa. Las mujeres, prevenidas al efecto, se han retirado y el encargado anuncia a voz en grito:
-Acomódate - Varios curiosos, y entre ellos Sandoval, se interesaron en la prueba. - Os aseguro que es buen varón entre varones $y$ hasta sabe rezar... Negro, rezad lo que os han enseñado jvamos, rezad, que no os pesará! Dios nuestro Señor también suele escuchar las oraciones de los negros.

-Padre nuestro..

— ¿Lo veis? Os lo dije ¡rezad, rezad!

El negro rezaba en castellano y luego lo hacía en latín. Entre oración y oración reía como si le estuvieran haciendo cosquillas en la planta del pie. El subastador habló y el negro repitió el rezo. Se reía y reía, como si supiera que el Dios blanco jamás habría de escuchar la oración de un negro. Parecía una figura de carbón tallada. El subastador tomó su pene entre los dedos y señalando con la otra mano, explicó:

-Ya lo veis, de luenga medida, bueno para las indias desde los doce hasta los cuarenta años... para que aumentéis vuestra hacienda. Hasta lo podéis alquilar, si tal deseáis... (1986: 263).

Este esclavo moriría más tarde, víctima de la peste, es decir, la viruela, en el propio palacio de Ahuízotl, mientras pronunciaba "palabras extrañas que ni siquiera los nuevos conocedores del castellano entendían" (1986: 265). Esta enfermedad causará estragos entre la población autóctona, será la misma enfermedad que casi arruina el bautizo de Tocolotzin, nuevo señor de Texcoco, designado tal por el propio Hernán Cortés. Disfrazado como español, la escena discurre:

La tropa se puso en actitud de firmes y presentó armas. En ese momento, ingresó el nuevo señor de Texcoco. Era Tecolotzin. Todos dejaron de reír cuando ingresó en el salón. Venía vestido a la sevillana, $y$ como era grande $y$ gordo, sus movimientos eran amorfos dentro de la vestidura. Su gran barriga le molestaba dentro de los jubones. Calzaba botas 
de Castilla y llevaba gorra estilo Cortés; espada al cinto, espuelas en los talones de las botas, que le costaba trabajo manejar. Ingresó sonriendo, pero tenía la cara pálida. Cortés se puso nervioso al verle y preguntó discreto:

— ¿No será la... enfermedad?

El sacerdote Juan Díaz y Fray Bartolomé de Olmedo habían preparado un altar lleno de flores del lago. Todo era rojo. En el acto se bautizaría al señor Tecolotzin.

- ¿Aceptáis ser el padrino del señor que en este acto bautizaremos con el nombre cristiano de don Fernando? preguntó Fray Bartolomé a Cortés. Este se hincó y en actitud de sumisión, respondió:

-Acepto.

Juan Díaz echó agua bendita sobre la cabeza de Tocolotzin en tanto murmuraba:

-Ego te bautizo in nómine Patre (sic), et Filii... (1986: 275).

Nuevamente, figura Patre en lugar de Patris, tal y como se ha apuntado. Este, así como los otros yerros no parecen denotar algún tipo de intencionalidad por parte del autor. Primero que todo, porque probablemente no serían percibidos por la mayoría de los lectores (lo que reduciría significativamente cualquier efecto que el autor hubiera deseado), segundo, porque más parecen deberse a errores de transcripción, quizá originados en que la citas fueron hechas de memoria, sin consultar una fuente fidedigna.

La guerra contra los aztecas era también una guerra lingüística, unos y otros procuran rápidamente aprender la lengua de su enemigo. Sin embargo, los invasores no soportan con facilidad el náhuatl, tal y como muestra la siguiente sentencia de Cortés:

—Calpan, iqué nombres más difíciles de pronunciar! Después de nuestra llegada a México, mandaré borrar estos nombres salvajes de nuestros enemigos aztecas, señora. Aquesta tierra ha de llamarse Nueva España y no habrá más tierras divididas, todo será una nación bajo nuestra bandera y al servicio de su Alteza Real, a quien Dios prodigue mucha fortuna... (1986: 122).

El registro religioso y su permanente amenaza a la libertad de los nativos se manifiesta sin velamen luego de la derrota de Tenochtitlan, cuando llegan ante Cortés doce misteriosos varones, "hombres descalzos, haraposos, barbudos, con el cansancio reflejado en sus ojos", que se llaman entre sí "hermanos", ante quienes el Capitán de Castilla se inclina y besa sus pies. Una ignota mujer azteca pregunta ¿quiénes son?, la respuesta es sencilla:

—Son los conquistadores... (1986: 404).

Era el grupo de frailes que venía a transmitir la buena nueva, el mensaje de Cristo.

Ya para este momento, el resultado de la lucha se aprecia lingüísticamente luego de la derrota de los tenochas: las órdenes "se dan en mal idioma de Tenochtitlan" (p. 403), pues ya no importa conocer y dominar la lengua de un pueblo que ya ha sido controlado en sus cuerpos y voluntades. Así lo habían presentido las palabras de Cuauhtémoc:

- Si perdemos esta guerra... solamente nos usarán para hacer cacharros... para cocer cacharros... nadie escuchará nunca más las palabras mexicanas... (1986: 394).

Luego de la derrota, la transformación es definitiva:

Cristóbal Flores estaba en la cima de un templo, ahora convertido en iglesia dedicada a María, madre de Dios, refugio de los pescadores, salvación de los cristianos... Madre de madres... Con un nombre raro, estaba esa diosa cristiana, como la diosa madre del mundo azteca (1986: 399).

En ese templo colgarán la Nicolasa, una campana:

(...) era como una niña vestida de fiesta para el Corpus, en las calles de Sevilla... 
y sonaba por el tiempo... Ton ton. Por lo que había sucedido... Tan tan tan. Por lo que estaba pasando... Ton ton ton. Por lo que sucedería esa mañana, a destiempo, que estaba ya pasando en la historia de México Tenochtitlan (1986: 399).

El contraste lingüístico es patente: el cambio de dominación implica una regresión lingüística, representada en la carencia de significante léxico de las onomatopeyas del repique de las campanas. Son arbitrarias, pero plurisignificativas.

En este contexto, el latín reaparece en la comparación con el Corpus, frase nominal elíptica del Corpus Christi. Es esta la penúltima aparición de esta lengua en la obra. La última tiene estrecha relación con esta, es el angelus:

La campana replicó seis veces... Ton... ton... ton... ton... ton... ton... Era la hora del angelus en el nuevo mundo de los cristianos. Hernán Cortés iba subiendo las ciento catorce gradas del Templo Mayor de Tenochtitlan (1986: 399).
Estos dos momentos aparecen imbricados merced al repicar de la campana. Ambos son representantes fieles de la ritualidad católica: no son expresiones racionales, son imposiciones del nuevo culto, reiterativas por los siglos de los siglos. Apelan este, al inicio de la cristiandad en el Misterio de la Anunciación, el otro, a su inicio en la institución de la Eucaristía, un sacrificio cruento renovado incruentamente en el ceremonial litúrgico por toda la eternidad, así es la historia, así es México.

\section{BIBLIOGRAFÍA}

De Alón Fontcuberta, Francisco. "Lemas heráldicos españoles”. Revista Hidalguía 44. 1961: 129-150.

León Sánchez, José. Tenochtitlan. La última batalla de los aztecas. $6^{\text {a }}$ edición. México: Editorial Grijalbo SA, 1986.

Fecha de ingreso: 14/04/2011

Fecha de aprobación: 18/01/2012 
